\title{
BMJ Open Dual burden of underweight and overweight/obesity among adults in Botswana: prevalence, trends and sociodemographic correlates: a cross- sectional survey
}

\author{
Gobopamang Letamo (D)
}

To cite: Letamo G. Dual burden of underweight and overweight/obesity among adults in Botswana: prevalence, trends and sociodemographic correlates: a crosssectional survey. BMJ Open 2020;10:e038614. doi:10.1136/ bmjopen-2020-038614

- Prepublication history for this paper is available online. To view these files, please visit the journal online (http://dx.doi org/10.1136/bmjopen-2020038614).

Received 25 March 2020 Revised 04 June 2020 Accepted 05 June 2020

\section{D) Check for updates}

(C) Author(s) (or their employer(s)) 2020. Re-use permitted under CC BY-NC. No commercial re-use. See rights and permissions. Published by BMJ.

Population Studies, University of Botswana, Gaborone, Botswana

Correspondence to

Professor Gobopamang Letamo; gobopamang.letamo@mopipi. ub.bw

\section{ABSTRACT}

Objective To estimate the prevalence and trends in underweight, overweight/obesity and identify their sociodemographic correlates among adults in Botswana from 2007 to 2017.

Design The study analysed cross-sectional and nationally representative data from 2007 to 2014 Botswana STEPS Surveys and the 2017 Botswana Demographic Survey.

Setting Botswana.

Participants Botswana adults aged $25-64$ years $(n=4003$ in 2007, $n=2983$ in 2014 and $n=11550$ in 2017).

Primary outcome Underweight and overweight/obesity. Results The prevalence of underweight decreased from $18.1 \%$ (95\% Cl $12.0 \%$ to $26.3 \%$ ) in 2007 to $11.6 \%$ (95\% Cl 9.5\% to 13.9\%) in 2014 and further dropped to $8.1 \%(95 \% \mathrm{Cl} 7.5 \%$ to $8.8 \%$ ) in 2017. The prevalence of overweight/obesity increased slightly from $37.4 \%$ (95\% Cl $34.3 \%$ to $40.7 \%$ ) in 2007 to $38.6 \%(95 \% \mathrm{Cl} 35.9 \%$ to $41.3 \%$ ) in 2014 to $47.3 \%$ (95\% Cl $46.1 \%$ to $48.4 \%$ ) in 2017. Underweight was more prevalent among males than females while overweight and obesity were more prevalent among females than males. The key risk factor for underweight was being male (adjusted OR (AOR) 2.21: $95 \% \mathrm{Cl} 1.80$ to 2.72 in $2007, \mathrm{AOR} 1.54: 95 \% \mathrm{Cl} 1.06$ to 2.22 in 2014 and AOR 1.51: $95 \% \mathrm{Cl} 1.45$ to 1.58 in 2017). For overweight/obesity, the main risk factors were being female (male AOR 0.23: $95 \% \mathrm{Cl} 0.15$ to 0.35 in 2007, AOR 0.32: $95 \% \mathrm{Cl} 0.25$ to 0.42 in 2014 and AOR $0.30: 95 \% \mathrm{Cl}$ 0.29 to 0.31 in 2017), being old (AOR 2.18: $95 \% \mathrm{Cl} 1.58$ to 3.01 in $2007, A O R$ 2.37: $95 \% \mathrm{Cl} 1.71$ to 3.29 in 2014) and AOR 2.10: $95 \% \mathrm{Cl} 1.94$ to 2.27 in 2017 among those aged 55-64 years) and not working (AOR 1.70: 95\% Cl 1.20 to 2.42 in 2007, AOR 2.05: $95 \% \mathrm{Cl} 1.55$ to 2.69 in 2014 and AOR 1.34: $95 \% \mathrm{Cl} 1.27$ to 1.40 in 2017).

Conclusions The findings presented in this study indicate coexistence of the double burden of underweight and overweight/obesity among adults aged 25-64 years in Botswana. Although underweight prevalence is on the decline, overweight/obesity is increasing over time. The problem of underweight and overweight/obesity needs immediate and effective interventions.

\section{Strengths and limitations of this study}

- To the author's knowledge, this is the first study to document the dual burden of underweight and overweight/obesity and trends in both underweight and overweight/obesity among adults in Botswana using similar nationally representative datasets, which are of enormous clinical and public health interest.

- The study contributes to our understanding of the sociodemographic risk factors associated with underweight and overweight/obesity.

- The analysis accounted for a complex survey design (clustering, stratification, sample weights) which gives accurate estimates of the population parameters.

- One of the major limitations is that some of the key variables known to be related to underweight and overweight/obesity were not included in the analysis because the datasets used did not contain them, such as wealth status, place of residence and marital status.

- Because the data were not derived from randomised control trial, no causal relationships can be inferred from the study results as the data used come from cross-sectional surveys. Because cross-sectional data refers to the situation of interest at a specific point in time, it is impossible to infer causality from it.

\section{INTRODUCTION}

Many low-income and middle-income countries are now facing a 'double burden' of disease: undernutrition and overweight/ obesity. ${ }^{1}$ WHO contends that it is not uncommon to find undernutrition and overweight/obesity coexisting within the same country, the same community and the same household. ${ }^{1}$ The consequences of both undernutrition and overweight and obesity are well known. While warnings about health consequences of excess weight abound, ${ }^{2-4}$ less attention appears to be paid to the 
simultaneous study of the double burden of both underweight and excess weight. ${ }^{1}$ Sub-Saharan Africa (SSA) has been mainly associated with undernutrition, HIV and tuberculosis but hardly with overweight and obesity until recently. ${ }^{5}$ Meanwhile research on overweight/obesity has started to gain significance in $\mathrm{SSA}^{6-8}$ due to its increasing magnitude.

An increase in non-communicable diseases (NCDs) and their effect in low-income and middle-income countries is a public health concern. At least 36 million people annually are killed by NCDs with almost $80 \%$ of NCD deaths taking place in low-income and middle-income countries. ${ }^{9}$ The annual contribution of each of the major NCD-related deaths are as follows: cardiovascular diseases account for 17 million deaths, cancers account for 7.6 million deaths, respiratory diseases account for 4.2 million deaths and diabetes account for 1.3 million deaths. ${ }^{9}$ Tobacco use, physical inactivity, harmful use of alcohol and unhealthy diet are the common risk factors shared by the four above-mentioned diseases. ${ }^{9}$

Being underweight or overweight is likely to lead to adverse health outcomes throughout the life course. ${ }^{10}$ The global NCD targets of halting, by 2025, the rise in the prevalence of obesity at its 2010 level have been driven largely by concerns about the health and economic burden of increasing body mass index (BMI). ${ }^{11}{ }^{12}$ Epidemiological studies have shown substantial risks in people with very high BMI, for example, severe $\left(\geq 35 \mathrm{~kg} / \mathrm{m}^{2}\right)$ or morbid $\left(\geq 40 \mathrm{~kg} / \mathrm{m}^{2}\right)$ obesity. ${ }^{13}$ It should also be noted that being underweight is also associated with increased risk of morbidity and mortality and with adverse pregnancy outcomes. ${ }^{14-17}$ There is a realisation that there are very few analyses of trends in underweight, ${ }^{18}$ especially for men.

There are rapid and major demographic and epidemiological changes that are taking place in some certain parts of SSA countries as shown by an ageing population, persisting communicable diseases such as HIV and tuberculosis and rising prevalence of NCDs such as hypertension and diabetes. ${ }^{19-22}$ Some scholars have observed that over the past 25 years, the prevalence of overnutrition has risen by more than $330 \%$, contributing to an upsurge in the burden of NCDs in Africa. ${ }^{6}$ However, there are variations in the levels of obesity on the African continent; for instance, in southern Africa consisting of Botswana, Lesotho, Namibia, South Africa and Swaziland (now Eswatini), obesity levels are highest. ${ }^{10}$ Botswana has one of the highest levels on the continent with $3.2 \%$ of males and $15.4 \%$ of females aged 20-49 years estimated to be obese and $12.9 \%$ of males and $23.3 \%$ of females in the same age group were estimated to be overweight in $2007 .{ }^{23}$ Estimates for undernutrition in Botswana were $16.5 \%$ for males and $11.2 \%$ for females in the same period. ${ }^{24}$

Despite the increasing number of people who are overweight and obese, SSA still lacks research in this area partly because of the persisting high percentage of the population classified as underweight. ${ }^{25}$ As such most of the nutritional research in SSA has tended to focus on under-nutrition, especially on the vulnerable populations such as women and children. ${ }^{25}$ The rapid process of both urbanisation and westernisation taking place in SSA is often associated with the current nutritional transition in these countries. ${ }^{26-30} \mathrm{~A}$ worrisome trend is that the number of deaths from NCDs in low-income and middleincome countries has already exceeded those observed in developed countries. ${ }^{31}{ }^{32}$ Given this information, it is imperative for each country to know the estimated prevalence and change in underweight and overweight/obesity so that this can be used as evidence by government to develop and implement appropriate intervention strategies. At the moment, Botswana does not have comparable information on the prevalence, trends and correlates of underweight and overweight/obesity. Therefore, the current research questions under investigation are: what is the prevalence of underweight and overweight/obesity among adults; how is it changing over time? And what are sociodemographic correlates of underweight and overweight/obesity?

In order to prevent further spread of NCDs in the general population, it is imperative that their prevalence, change over time and their common risk factors which are measurable and amenable to intervention be identified. We used nationally representative data collected using similar methods to estimate the prevalence and trends in underweight, overweight/obesity and their sociodemographic correlates among adults aged 25-64 years in Botswana.

\section{METHODS}

\section{Study design}

The current analysis is based on three cross-sectional, population-based surveys. The first Botswana STEPwise approach to Surveillance (STEPS) Survey was conducted in 2007 while the Botswana STEPS Survey II was conducted in 2014. The 2007 Botswana STEPS Survey adopted a multistage cluster sampling methodology to arrive at the selected sample of adults aged $25-64 .{ }^{33}$ The 2014 Botswana STEPS Survey used systematically sampled enumeration areas of the districts to produce representative data for 15-69 age groups. ${ }^{34}$ A detailed report on the methodology of each Botswana STEPS Surveys has been presented elsewhere. ${ }^{334}$ The 2017 Botswana Demographic Survey (BDS) was based on all persons in the household but all of the data used in this paper were restricted to those aged 25-64 years. The 2017 BDS adopted a stratified two-stage probability sampling design to produce a sample representative of the target population. A detailed report on the methodology of the 2017 BDS has been presented elsewhere. ${ }^{35}$

\section{Data}

This study is based on secondary data analysis of the population-based 2007 and 2014 Botswana STEPS surveys and the 2017 BDS. The 2007 STEPS survey focused on the 25-64year-olds. Because the two surveys covered 
different age groups the survey analysis was restricted to adults aged 25-64 years old in order to make the analysis comparable between the three surveys. Since data used in the surveys represent only the participants sampled, the data were weighted to make them nationally representative of the participants aged 25-64 years.

\section{Sampling procedure}

Since a multistage stratified sampling procedure was used in the two STEPS Surveys, the use of standard statistical methods for analysing the data would produce incorrect standard errors for the survey estimates because the methods assume simple random sampling procedure was used. As such during analysis of data, a complex sample module from SPSS was adopted to ensure that the estimated standard errors for the survey estimates are robust to bias and correctly reflect sampling variability. The target sample size for the 2007 Botswana STEPS Survey was 4000 but was oversampled by 15 individuals although ultimately the refined sample size was 4003 adults aged 25-64 years, yielding a response rate of $100 \% .{ }^{33}$ The target sample size for the 2014 Botswana STEPS Survey was 6410 but 4074 individuals participated, yielding an overall response rate of $64 \% .{ }^{34}$ The targeted sample size was not reached for various reasons that include: shortage of transport, inadequate survey equipment, personal digital assistant (PDA)'s non-functionality, loss of data after being entered into PDA, time-consuming process of finding sampled houses in enumeration areas and long distances between households, among others. ${ }^{34}$ The 2017 BDS target sample size was 622 enumeration areas but due to resource constraints this sample size was reduced by $23 \%$, which yielded a sample of 478 enumeration areas. ${ }^{35}$ The sampled 478 enumeration areas yielded a sample of 9560 households. ${ }^{35}$

\section{Measures}

\section{Outcome variables}

The dependent variables are (1) underweight; (2) overweight and (3) obesity. Height was measured using portable height/length measuring board while weight was measured using portal electronic weighing scale. Height was measured in centimetres during the survey but was later converted to metres during the analysis. Height was restricted to $1.0-2.7 \mathrm{~m}$ while weight was restricted to $20-350 \mathrm{~kg}$ as per the recommendation of WHO. Using these restrictions, $3.8 \%$ of participants were excluded on height in 2007 and all other years no one was excluded. For weight, $0.1 \%$ in 2014 and $1.1 \%$ in 2017 of the participants were excluded. In this study, BMI is categorised into four groups as per WHO recommendations: underweight (BMI $\left.<18.5 \mathrm{~kg} / \mathrm{m}^{2}\right)$, normal $\left(18.5 \mathrm{~kg} / \mathrm{m}^{2} \leq \mathrm{BMI}<\right.$ $\left.25 \mathrm{~kg} / \mathrm{m}^{2}\right)$, overweight $\left(25 \mathrm{~kg} / \mathrm{m}^{2} \leq \mathrm{BMI}<30 \mathrm{~kg} / \mathrm{m}^{2}\right)$ and obese (BMI $\geq 30 \mathrm{~kg} / \mathrm{m}^{2}$ ). The outcome variable is based on underweight versus normal weight and overweight/ obesity versus normal weight respectively for use with respect to logistic regression analyses.

\section{Sociodemographic variables}

The independent variables used for analysis in this study were selected on the basis of literature review and on the availability of the limited sociodemographic variables collected by the STEPS surveys and BDS. The following variables were collected in all the surveys: sex, age, nationality and work. Age was categorised as follows: 25-34, 35-44, 45-54 and 55-64. Citizenship variable was created into two categories, Motswana (a citizen of Botswana and Batswana refers to citizens of Botswana, plural) or others. Work status was created into two categories as working or not working. Participants who described their main work status over the past year as government employee, parastatal, non-governmental employee, self-employed were classified as working and those in non-paid/unpaid family helper, student, homemaker/housework, retired, unemployed (able to work) and unemployed (unable to work) as not working. Other key sociodemographic factors such as wealth status, place of residence and marital status were not used in the analyses because not all the datasets used had collected this information. Therefore, to maintain consistency across surveys, only those variables that appeared in all the three surveys were used.

\section{Statistical analysis}

Unweighted data were used to study the characteristics of the participants. The data were weighted to adjust for differential selection probabilities because the sample design involves more than one stage of selection. This ensures that data are representative of the target population, in this case, the 25-64years old. The data were weighted using sample weights. In order to ensure the changes in age distribution do not affect trends of the overall estimates, age-standardised proportions were computed using the 2011 Botswana Population and Housing Census data as a standard population. As such both unstandardised (true population prevalence rates) and standardised prevalence rates (hypothetical prevalence rates) are presented. Since the standard analytical procedures in traditional statistical package assume that the observations in the data represent a simple random sample from the population of interests, a complex sample procedure in SPSS was used. Complex sample procedure enables the researcher to achieve more statistical valid inferences for populations measured in complex sample data because it incorporates the sample design into the survey analysis. As such complex sample module in SPSS was used to estimate the prevalence and sociodemographic risk factors of underweight and overweight/ obesity. For the logistic regression analysis, the outcome indicator variables were based on underweight versus normal weight and overweight/obesity versus normal weight categories, respectively, where normal weight is the reference category. CIs were used to estimate the precision of the percentages and odds ratios. In order to determine sociodemographic correlates of underweight and overweight/obesity, all the datasets were used. Multivariable logistic regression analyses were used. ORs and 
Table 1 Sociodemographic characteristics of the samples, 2007 and 2014

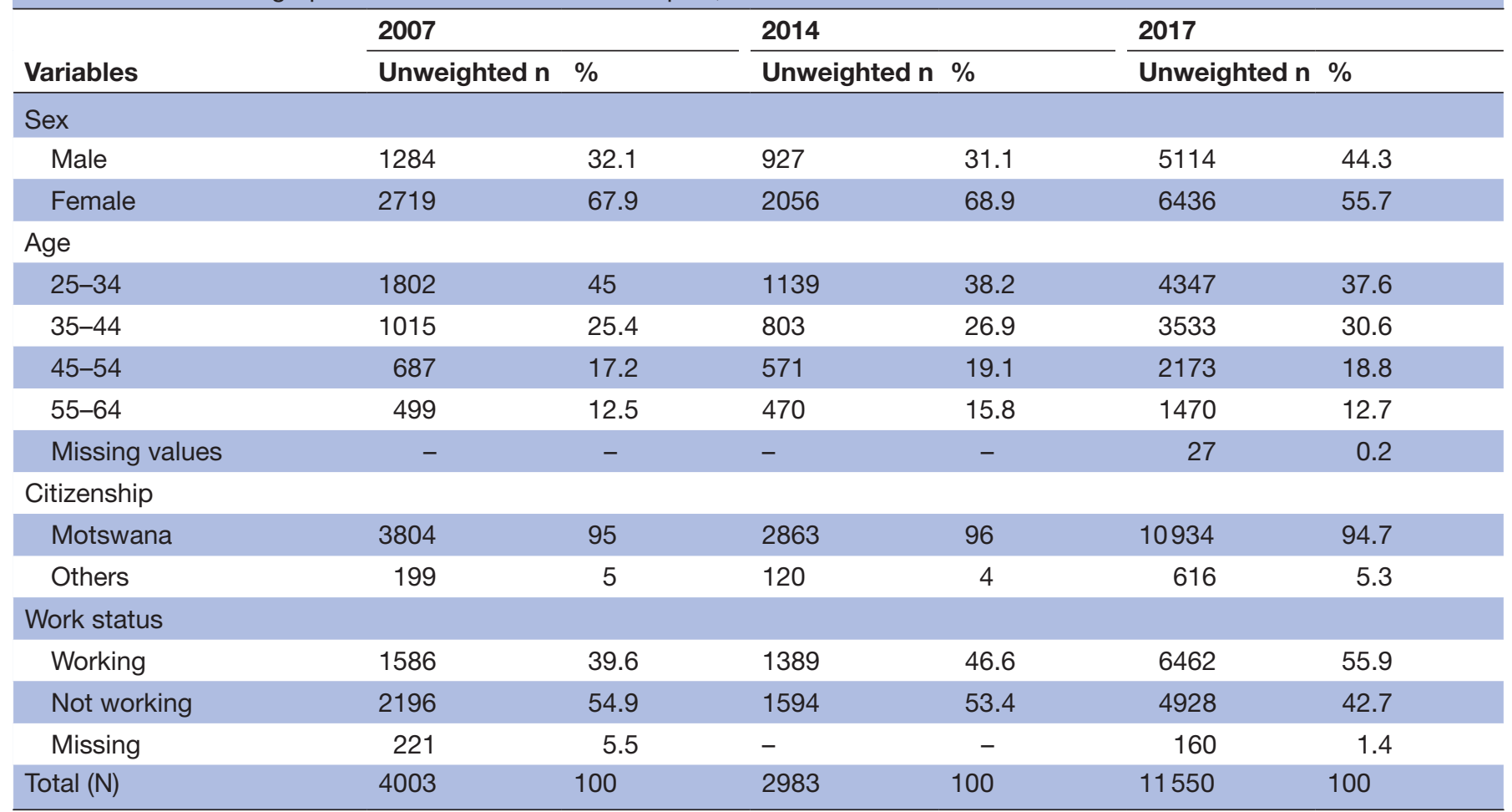

95\% CIs after adjusting for covariates were estimated and presented. All the statistical analyses were done in SPSS V.25. ${ }^{36}$

\section{Ethics statement}

The current analysis is based on the use of secondary datasets from Ministry of Health and Wellness and WHO and Statistics Botswana.

\section{Patient and public involvement}

The study used secondary data and therefore the outcome and predictor measures used in the study were those already existent in the datasets. Therefore, no patients were involved in the design, development of research question and outcome measures. The results will be disseminated to study participants through the preparation of policy briefs and presentations in conferences.

\section{RESULTS}

\section{Sociodemographic characteristics of study participants}

Table 1 presents sociodemographic characteristics of the study participants aged 25-64 years in 2007, 2014 and 2017. The proportion of male participants remained virtually the same between 2007 and 2014, 32.1\% and $31.1 \%$, respectively, but rose to $44.3 \%$ in 2017 . The percentage of respondents aged 45 and above rose from about $30 \%$ in 2007 to approximately $35 \%$ in 2014 and $31.5 \%$ in 2017. The proportion of the study participants who were Batswana (refers to citizens of Botswana) also remained similar between 2007, 2014 and 2017, 95.0\%, 96.0\% and $95 \%$, respectively while the proportion working rose slightly between 2007 and 2014 from $40 \%$ to $47 \%$ and finally to $56 \%$ in 2017 .

\section{Prevalence and trends in the prevalence of underweight and overweight/obesity}

The prevalence of underweight decreased from $18.1 \%$ in $2007,11.6 \%$ in 2014 and to $8.2 \%$ in 2017 while the prevalence of overweight/obesity rose from $37.4 \%$ to $38.6 \%$ and to $47.3 \%$ during the same time period (see figure 1 ).

Underweight was more prevalent among males than females while overweight and obesity were more prevalent among females than males throughout the three periods, 2007, 2014 and 2017. The largest decrease in underweight was more pronounced among males but small among females, 10.7 percentage points between 2007 and 2014 and 3.3 percentage points between 2014 and 2017 among males (see table 2). Another largest decline in underweight was observed among the 25-34 and 35-44years old especially between 2007 and 2014, 6.4 and 10.6 percentage points, respectively. From this table, it is clear that underweight is more prevalent among males, among Batswana and those not working.

Table 3 shows the prevalence and trends in overweight/obesity by sociodemographic variables. Overall, overweight/obesity increased from $37.4 \%$ in 2007 to $38.6 \%$ in 2014 and to $47.3 \%$ in 2017 . The increase was largest among males between 2007 and 2014 and largest among females between 2014 and 2017. Similar trends can be observed from age-standardised prevalence rates which showed an increase of overweight/obesity from $36.3 \%$ in 2007 to $38.7 \%$ in 2014 and ultimately $46.4 \%$ in 


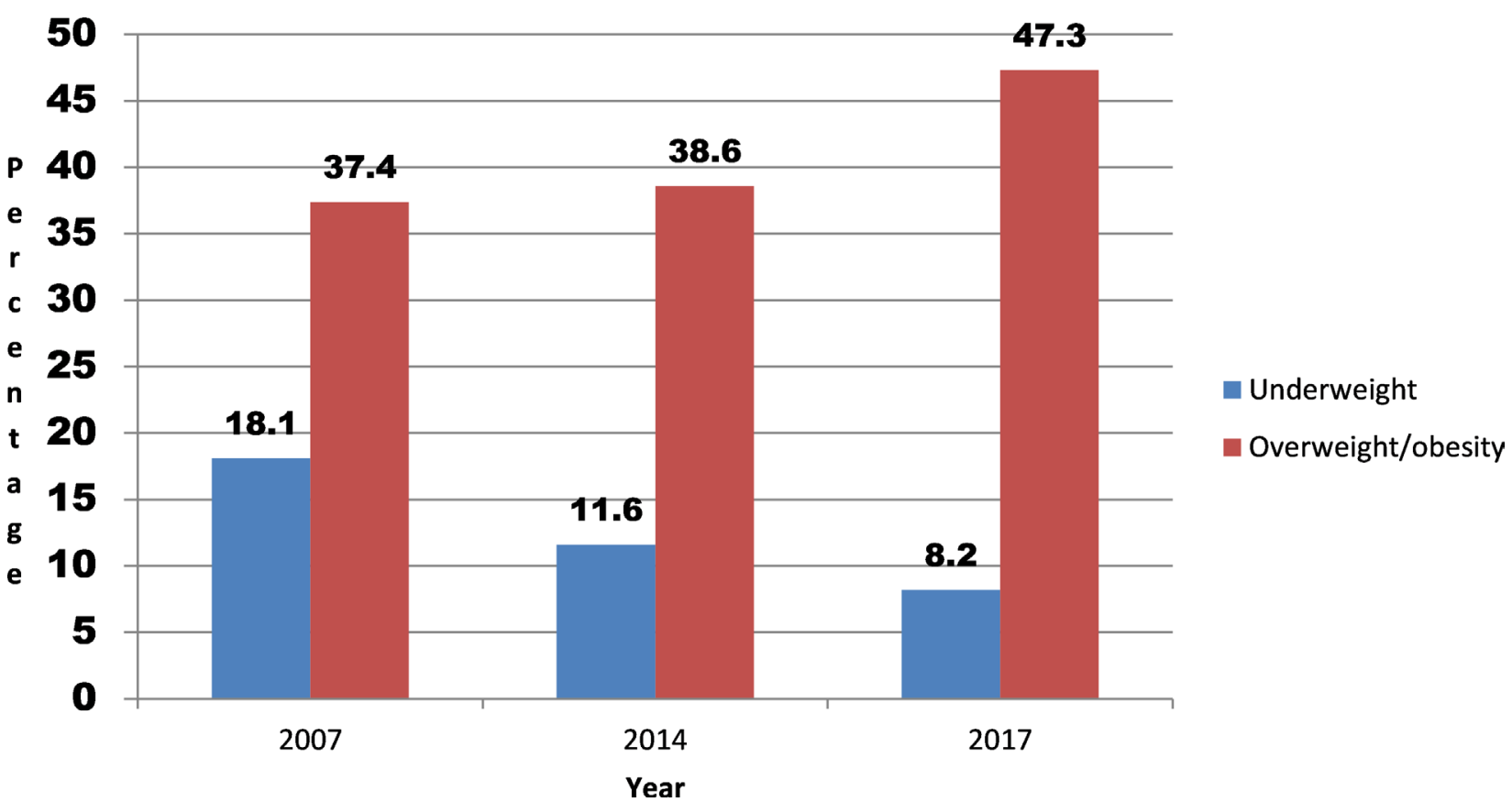

Figure 1 Trends in underweight and overweight/obesity in Botswana 2007-2017.

2017. Overweight/obesity increased from $21.3 \%$ in 2007 to $26.6 \%$ in 2014 and to $31.1 \%$ in 2017 among males while it decreased slightly among females from $52.3 \%$ in 2007 to $51.1 \%$ in 2014 but increased to $59.7 \%$ in 2017.
Overweight/obesity was more prevalent among females, the older participants and those working.

Table 2 Levels and trends in the prevalence of underweight by various sociodemographic variables, Botswana STEPS surveys 2007 and 2014

\begin{tabular}{|c|c|c|c|c|c|c|}
\hline \multirow[b]{2}{*}{ Variables } & \multicolumn{2}{|c|}{2007 STEPS survey } & \multicolumn{2}{|c|}{2014 STEPS survey } & \multicolumn{2}{|c|}{$\begin{array}{l}\text { Survey } \\
\text { Sutrana Demograpnic }\end{array}$} \\
\hline & Weighted $\mathbf{n}$ & $\%(95 \% \mathrm{Cl})$ & Weighted $\mathbf{n}$ & $\%(95 \% \mathrm{Cl})$ & Weighted $\mathbf{n}$ & $\%(95 \% \mathrm{Cl})$ \\
\hline \multicolumn{7}{|l|}{ Sex } \\
\hline Male & 9280 & 25.9 (16.1 to 38.9$)$ & 34936 & $15.2(12.2$ to 18.8$)$ & 43621 & 11.9 (10.9 to 12.9$)$ \\
\hline Female & 4261 & $10.9(7.9$ to 14.8$)$ & 16799 & 7.7 (5.8 to 10.1$)$ & 24485 & $5.2(4.8$ to 5.7$)$ \\
\hline \multicolumn{7}{|l|}{ Age } \\
\hline $25-34$ & 5797 & 20.0 (12.7 to 30.2$)$ & 27645 & 13.6 (10.6 to 17.3$)$ & 27541 & 8.6 (7.6 to 9.7$)$ \\
\hline $35-44$ & 3431 & $18.0(9.7$ to 30.9$)$ & 8913 & $7.4(5.0$ to 10.9$)$ & 18405 & $7.2(6.3$ to 8.2$)$ \\
\hline $45-54$ & 2749 & 16.4 (12.6 to 21.1$)$ & 7726 & 10.7 (6.3 to 17.6$)$ & 13169 & $8.4(7.7$ to 9.3$)$ \\
\hline $55-64$ & 1564 & 15.3 (7.3 to 29.3$)$ & 7448 & $14.3(9.2$ to 21.5$)$ & 8991 & $8.6(7.6$ to 9.6$)$ \\
\hline Missing values & - & - & 3 & - & - & - \\
\hline \multicolumn{7}{|l|}{ Citizenship } \\
\hline Motswana & 12991 & 18.2 (12.1 to 26.5 ) & 50580 & $11.9(9.8$ to 14.3$)$ & 66516 & $8.5(7.8$ to 9.1$)$ \\
\hline Others & 550 & 15.2 (9.5 to 23.5$)$ & 1155 & $5.4(1.4$ to 18.5$)$ & 1590 & 3.2 (2.4 to 4.3$)$ \\
\hline \multicolumn{7}{|l|}{ Work status } \\
\hline Working & 4169 & 14.2 (9.5 to 20.6$)$ & 21688 & 9.7 (7.4 to 12.8$)$ & 33866 & $7.2(6.7$ to 7.6$)$ \\
\hline Not working & 8379 & 20.6 (14.1 to 29.2 ) & 30047 & 13.4 (10.4 to 17.0$)$ & 33120 & 9.4 (8.3 to 10.6$)$ \\
\hline Missing values & 993 & - & - & - & 1120 & - \\
\hline Total $(\mathrm{N})$ & 13541 & 18.1 (12.0 to 26.3 ) & 51735 & 11.6 (9.5 to 13.9$)$ & 68106 & 8.1 (7.5 to 8.8$)$ \\
\hline Age adjusted & & 18.2 (12.1 to 26.2$)$ & & 11.5 (9.4 to 13.8$)$ & & 8.2 (7.6 to 8.9$)$ \\
\hline
\end{tabular}

The bolded figures show percentages and total sample size under each survey 
Table 3 Levels and trends in the prevalence of overweight/obesity by various sociodemographic variables, 2014

\begin{tabular}{|c|c|c|c|c|c|c|}
\hline \multirow[b]{2}{*}{ Variables } & \multicolumn{2}{|c|}{2007 STEPS survey } & \multicolumn{2}{|c|}{2014 STEPS survey } & \multicolumn{2}{|c|}{$\begin{array}{l}2017 \text { Botswana Demographic } \\
\text { Survey }\end{array}$} \\
\hline & Weighted $\mathbf{n}$ & $\%(95 \% \mathrm{Cl})$ & Weighted $\mathbf{n}$ & $\%(95 \% \mathrm{Cl})$ & Weighted $\mathrm{n}$ & $\%(95 \% \mathrm{Cl})$ \\
\hline \multicolumn{7}{|l|}{ Sex } \\
\hline Male & 7614 & 21.3 (14.5 to 30.0$)$ & 61073 & 26.6 (22.8 to 30.9 ) & 114145 & 31.1 (29.7 to 32.6 ) \\
\hline Female & 20464 & $52.3(49.8$ to 54.7$)$ & 111642 & 51.1 (48.0 to 54.2 ) & 280448 & 59.7 (58.7 to 60.7 ) \\
\hline \multicolumn{7}{|l|}{ Age } \\
\hline $25-34$ & 8006 & 27.6 (24.0 to 31.7$)$ & 62614 & 30.8 (27.3 to 34.6 ) & 125709 & 39.3 (37.3 to 41.4$)$ \\
\hline $35-44$ & 7935 & 41.6 (36.6 to 46.9$)$ & 50268 & 41.9 (36.2 to 47.8$)$ & 128730 & 50.3 (48.6 to 52.0 ) \\
\hline $45-54$ & 7664 & 45.8 (38.6 to 53.2 ) & 34604 & 47.9 (41.3 to 54.5$)$ & 83791 & 53.7 (51.6 to 55.9 ) \\
\hline $55-64$ & 4473 & 43.6 (36.0 to 51.5 ) & 25229 & 48.5 (42.6 to 54.4 ) & 56363 & 53.9 (52.2 to 55.6$)$ \\
\hline \multicolumn{7}{|l|}{ Citizenship } \\
\hline Motswana & 26738 & 37.5 (34.2 to 40.8$)$ & 163066 & 38.2 (35.5 to 41.0$)$ & 366907 & 46.6 (45.4 to 47.8$)$ \\
\hline Others & 1340 & 37.1 (31.9 to 42.7$)$ & 9489 & 45.2 (31.7 to 59.5$)$ & 27686 & 56.1 (52.9 to 59.3 ) \\
\hline Missing values & - & - & 160 & - & - & - \\
\hline \multicolumn{7}{|l|}{ Work status } \\
\hline Working & 11414 & 38.7 (34.0 to 43.7$)$ & 99343 & 44.6 (40.5 to 48.8$)$ & 234722 & 48.7 (47.2 to 50.2$)$ \\
\hline Not working & 14864 & 36.6 (32.5 to 40.9 ) & 73372 & 32.6 (29.2 to 36.2 ) & 159871 & 45.4 (44.2 to 46.5$)$ \\
\hline Missing values & 1800 & - & - & - & - & - \\
\hline Total (N) & 28078 & 37.4 (34.3 to 40.7 ) & 172715 & 38.6 (35.9 to 41.3 ) & 394593 & $47.3(46.1$ to 48.4$)$ \\
\hline Age adjusted & & 36.3 (33.2 to 39.6$)$ & & 38.7 (36.0 to 41.4$)$ & & 46.4 (45.2 to 47.5$)$ \\
\hline
\end{tabular}

The bolded figures show percentages and total sample size under each survey

Sociodemographic factors associated with underweight

In the univariate analysis, underweight was associated with the males, among Batswana in all the surveys and those not working in 2007 and 2017. After adjusting for potential confounders such as age, citizenship and working status, males were more likely to be underweight than female participants (adjusted OR (AOR) 2.21, 95\% CI 1.80 to 2.72) in 2007; (AOR 1.54, 95\% CI 1.06 to 2.22) in 2014 and (AOR 1.51, 95\% CI 1.45 to 1.58) in 2017. Not working participants were less likely to be underweight. AORs showed that participants not working were 52\% less likely to be underweight in 2007. All these associations were statistically significant at $5 \%$ level. In 2014, participants who were classified as not working were $8 \%$ less likely to be underweight and in 2017 participants who were not working were $22 \%$ less likely to be underweight. All other risk factors were not statistically significant (see table 4).

\section{Sociodemographic factors associated with overweight and obesity}

Table 5 shows ORs of being overweight/obese by sociodemographic factors. Adjusted AORs showed that overweight/obesity was significantly associated with being female, being old and not working (see table 5). Adjusted AORs for being overweight/obese for males were as follows: (AOR 0.23, 95\% CI 0.15 to 0.35 ) in 2007 and (AOR 0.32, 95\% CI 0.25 to 0.42) in 2014 and (AOR 0.30,
95\% CI 0.29 to 0.31 ) in 2017. Adults in all age groups 35-44 years and above were also generally more likely to be overweight/obesity. For example, adults aged 55-64 years were approximately two times more likely to be overweight/obese than those aged 25-34 years in all the years under study participants who were not working were more likely to be overweight/obese. The adjusted AORs were as follows: AOR $1.70,95 \%$ CI 1.20 to 2.42 in 2007; AOR 2.04, 95\% CI 1.55 to 2.69 in 2014 and AOR 1.34, 95\% CI 1.27 to 1.40 in 2017. Citizenship also showed a statistically significant difference between Batswana and other nationalities: AOR 0.61, 95\% CI 0.55 to 0.68 in 2017.

\section{DISCUSSION}

The study set out to investigate the prevalence, trends and sociodemographic correlates of underweight and overweight/obesity between 2007 and 2017 in Botswana. The study clearly demonstrated coexistence of a dual burden of underweight and overweight/obesity among adults aged 25-64 years in 2007, 2014 and 2017, although underweight prevalence was decreased while overweight/ obesity increased substantially in the period under study. The study also observed that the key sociodemographic risk factor of underweight was being male while those of overweight/obesity were being female, old age and not working. These results are consistent with previous studies conducted in the country. ${ }^{23}{ }^{24}$ Since the data 


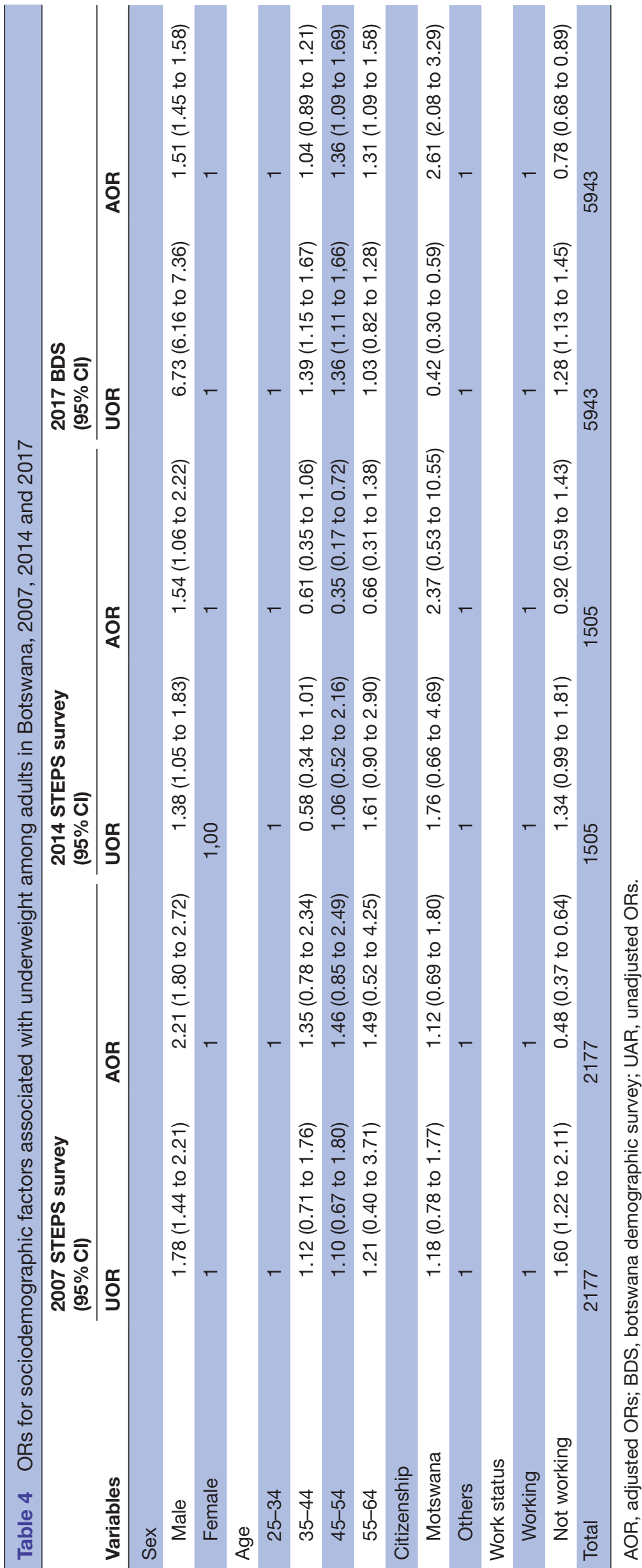

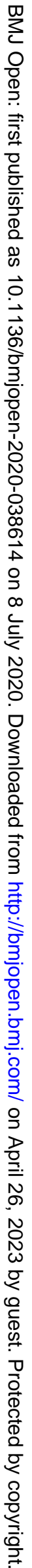




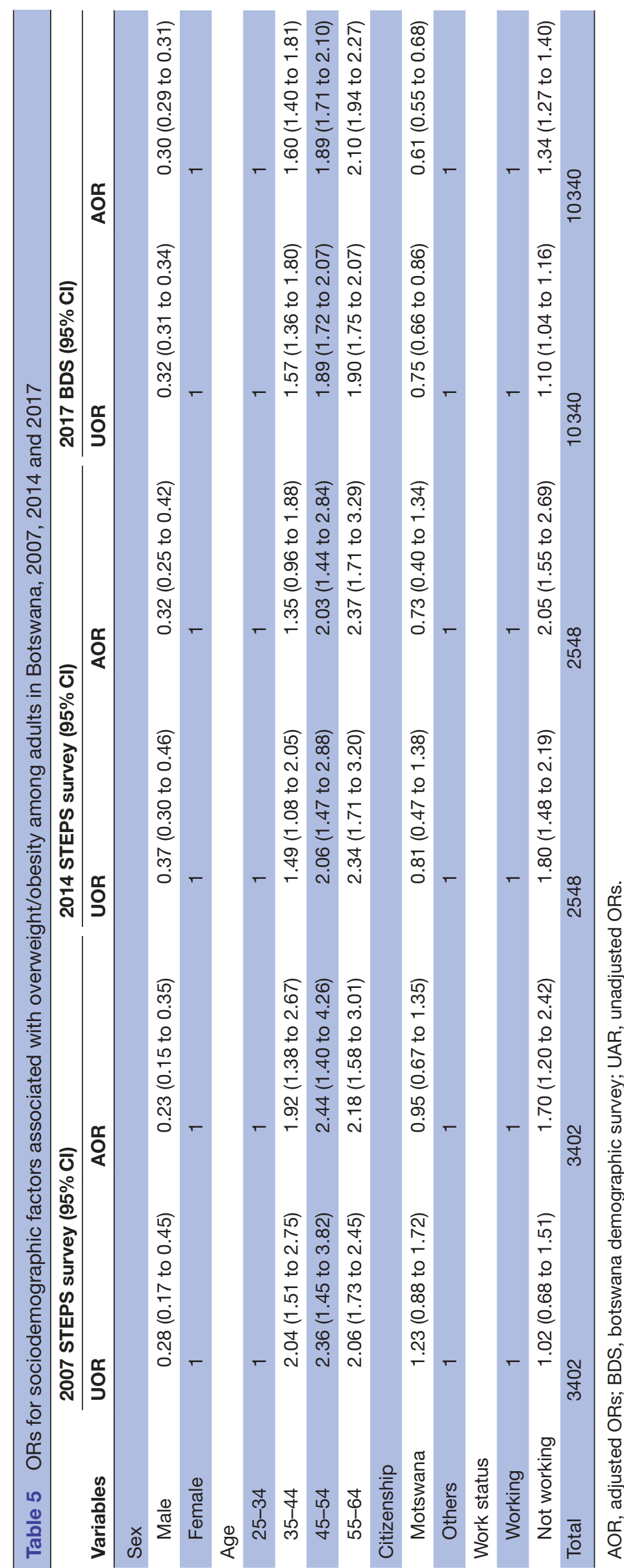

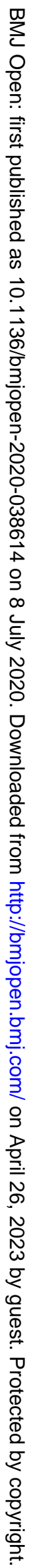


represent adults aged 25-64 years in Botswana, the study results can be generalised to the general population in that age group. The high prevalence of underweight among males than females in Botswana contrasts with the trends observed in South Asian countries where the opposite is true. South Asian studies demonstrate that adult females were more likely to be both underweight and overweight. ${ }^{37-40}$

Trends in underweight between 2007 and 2017 indicate that prevalence of underweight is declining over the years while that of overweight/obesity in rising. It has been observed that nutrition transition, changes in lifestyles, rapid urbanisation, increasing incomes, consumption of high-fat food coupled with lack of physical activity are the major causes of overweight/obesity epidemic in SSA. ${ }^{141-43}$ Previous studies have shown that about $82 \%$ of people in Botswana eat insufficient fruit and vegetables, $13 \%$ consume alcohol, $12 \%$ used tobacco and about $52 \%$ of the respondents reported engaging no or low level of physical activity. ${ }^{44}$ These high prevalence rates of modifiable unhealthy behaviours can help us understand why overweight/obesity is increasing in Botswana. In Botswana, as in other parts of the world, it has been observed that hypertension was more prevalent among those who were obese. ${ }^{45}$

The study results also demonstrate that the prevalence of underweight is highest among males. Undernourishment is known to compromise the health of adults. For example, it has been observed that undernourished elderly have longer periods of illness, longer hospital stays, higher rates of infection, delayed wound healing, reduced appetite, increased mortality rate and adverse pregnancy outcomes. ${ }^{46}$ The reasons for high prevalence of underweight among men remain unknown because men tend to eat food richer in fats and proteins, to drink more wine, beer, spirits and sweet carbonated drink; in general, they show dietary behaviours potentially favouring overweight and obesity. ${ }^{47}$ Further studies need to be conducted that investigates why men are underweight despite their eating behaviours which are likely to promote overweight/obesity. These studies should explore the behavioural patterns of men that increase their likelihood of becoming underweight.

Since this study is based on cross-sectional data, no causal relationships can be deduced from this type of data. However, the ORs were used to determine how different sociodemographic factors are risk factors to either underweight or overweight/obesity. One of the major limitations is that some of the key variables known to be related to nutritional status were not included in the analysis because the datasets used did not contain them, such as wealth status, place of residence and marital status. The study restricted itself to sociodemographic correlates and as such cannot explain the behavioural aspects of malnutrition. Apart from physical measurements of height and weight used for calculating BMI, sociodemographic data were collected from self-reports which may not necessarily be accurate. It should also be noted that while BMI is often used as an indicator for obesity, BMI does not always reflect adiposity or body fatness. This is because BMI is unable to distinguish between fat and muscle, which tends to be heavier and can tip more toned individuals into overweight status. BMI does not accurately reflect visceral fat accumulation, the likely culprit leading to most of the metabolic and clinical consequences of obesity. ${ }^{48}$

\section{CONCLUSION}

Botswana has a dual burden of underweight and overweight/obesity among adults. Although the prevalence of underweight has been decreasing between 2007 and 2017, it was evident that the burden of overweight/ obesity increased among adults in Botswana in the same period. The key sociodemographic correlates of underweight was being male while those of overweight/obesity were being female, being old and not working. It is, therefore, imperative that immediate interventions are designed and implemented to tackle the dual burden of underweight and overweight/obesity in order to alleviate problems associated with malnutrition. Further research is necessary to unravel other risk factors associated with underweight and overweight/obesity which were not contained in the current datasets. It is also necessary to investigate the underlying behavioural factors for underweight and overweight/obesity such as reasons for low fruit and vegetable consumption, alcohol consumption and tobacco use.

Acknowledgements The datasets used in this study were obtained from the Ministry of Health and Wellness in Botswana and WHO. The author wishes to thank both the Ministry of Health and Wellness in Botswana and WHO profusely for allowing him to use the data sets. However, any content of this article remains the responsibility of the author.

Contributors The manuscript was written by a single author. The author conceptualised, reviewed literature, analysed data and wrote the manuscript singlehandedly. As such there are no other authors to cite in this manuscript.

Funding The authors have not declared a specific grant for this research from any funding agency in the public, commercial or not-for-profit sectors.

Competing interests None declared.

Patient consent for publication Not required.

Provenance and peer review Not commissioned; externally peer reviewed.

Data availability statement Data may be obtained from a third party by writing directly to WHO NCD Microdata Repository (https://extranet.who.int/ncdmicrodata/ index.php/home, Ministry of Health and Wellness and Statistics Botswana Offices).

Open access This is an open access article distributed in accordance with the Creative Commons Attribution Non Commercial (CC BY-NC 4.0) license, which permits others to distribute, remix, adapt, build upon this work non-commercially, and license their derivative works on different terms, provided the original work is properly cited, appropriate credit is given, any changes made indicated, and the use is non-commercial. See: http://creativecommons.org/licenses/by-nc/4.0/.

ORCID iD

Gobopamang Letamo http://orcid.org/0000-0001-7256-4700

\section{REFERENCES}

1 World Health Organisation. Obesity. Available: https://www.afro.who. int/health-topic/obesity 
2 Pi-Sunyer FX. Medical hazards of obesity. Ann Intern Med 1993;119:655-60.

3 Berg C, Rosengren A, Aires N, et al. Trends in overweight and obesity from 1985 to 2002 in Göteborg, West Sweden. Int J Obes 2005;29:916-24.

4 Must A, Spadano J, Coakley EH, et al. The disease burden associated with overweight and obesity. JAMA 1999;282:1523-9.

5 Micklesfield LK, Lambert EV, Hume DJ, et al. Socio-cultural, environmental and behavioural determinants of obesity in black South African women. Cardiovasc J Afr 2013;24:369-75.

6 Abubakari AR, Lauder W, Agyemang C, et al. Prevalence and time trends in obesity among adult West African populations: a metaanalysis. Obes Rev 2008;9:297-311.

7 Ziraba AK, Fotso JC, Ochako R. Overweight and obesity in urban Africa: a problem of the rich or the poor? BMC Public Health 2009;9:465

8 Mayosi BM, Flisher AJ, Lalloo UG, et al. The burden of non-communicable diseases in South Africa. The Lancet 2009;374:934-47.

9 African Union. The Impact of Non-Communicable Diseases (NCDs) and Neglected Tropical Diseases (NTD) on Development in Africa. Ethiopia: Sixth Session of African Union Conference of Ministers of Health Addis Ababa, 2013: 22-6.

10 NCD Risk Factor Collaboration (NCD-RisC). Worldwide trends in body-mass index, underweight, overweight, and obesity from 1975 to 2016: a pooled analysis of 2416 population-based measurement studies in 128.9 million children, adolescents, and adults. Lancet 2017;390:2627-42

11 World Health Organisation (WHO). Global action for the prevention and control of noncommunicable diseases 2013-2020. Geneva, Switzerland: World Health Organisation, 2013.

12 Kontis V, Mathers CD, Rehm J, et al. Contribution of six risk factors to achieving the $25 \times 25$ non-communicable disease mortality reduction target: a modelling study. Lancet 2014;384:427-37.

13 Kitahara CM, Flint AJ, Berrington de Gonzalez A, et al. Association between class III obesity (BMI of $40-59 \mathrm{~kg} / \mathrm{m} 2$ ) and mortality: a pooled analysis of 20 prospective studies. PLoS Med 2014;11:e1001673.

14 Zheng W, McLerran DF, Rolland B, et al. Association between bodymass index and risk of death in more than 1 million Asians. $N$ Engl $J$ Med 2011;364:719-29.

15 Prospective Studies Collaboration, Whitlock G, Lewington S, et al. Body-Mass index and cause-specific mortality in 900000 adults: collaborative analyses of 57 prospective studies. Lancet 2009;373:1083-96.

16 Black RE, Victora CG, Walker SP, et al. Maternal and child undernutrition and overweight in low-income and middle-income countries. Lancet 2013;382:427-51.

17 Han Z, Mulla S, Beyene J, et al. Maternal underweight and the risk of preterm birth and low birth weight: a systematic review and metaanalyses. Int J Epidemiol 2011;40:65-101.

18 Mamun AA, Finlay JE. Shifting of undernutrition to overnutrition and its determinants among women of reproductive ages in the 36 low to medium income countries. Obes Res Clin Pract 2015;9:75-86.

19 Collinson MA, White MJ, Bocquier P, et al. Migration and the epidemiological transition: insights from the Agincourt sub-district of northeast South Africa. Glob Health Action 2014;7:23514.

20 Mayosi BM, Flisher AJ, Lalloo UG, et al. The burden of noncommunicable diseases in South Africa. Lancet 2009;374:934-47.

21 Streatfield PK, Khan WA, Bhuiya A, et al. Mortality from external causes in Africa and Asia: evidence from indepth health and demographic surveillance system sites. Glob Health Action 2014;7:25366.

22 Wagner RG, Crowther NJ, Gómez-Olivé FX, et al. Sociodemographic, socioeconomic, clinical and behavioural predictors of body mass index vary by sex in rural South African adults-findings from the AWIGen study. Glob Health Action 2018;11:1549436.
23 Letamo $\mathrm{G}$. The prevalence of, and factors associated with, overweight and obesity in Botswana. J Biosoc Sci 2011;43:75-84.

24 Letamo G, Navaneetham K. Prevalence and determinants of adult under-nutrition in Botswana. PLoS One 2014;9:e102675.

25 Kandala N-B, Stranges S. Geographic variation of overweight and obesity among women in Nigeria: a case for nutritional transition in sub-Saharan Africa. PLoS One 2014:9:e101103.

26 Vorster $\mathrm{HH}$, Wissing MP, Venter CS, et al. The impact of urbanization on physical physiological and mental health of Africans in the North West Province of South Africa: the THUSA study. S Afr $j$ 2000;96:505-13.

27 Griffiths PL, Bentley ME. The nutrition transition is underway in India. J Nutr 2001;131:2692-700.

28 Martorell R, Khan LK, Hughes ML, et al. Obesity in women from developing countries. Eur J Clin Nutr 2000;54:247-52.

29 Popkin BM. The nutrition transition in the developing world. Development Policy Review 2003;21:581-97.

30 Loaiza E. Maternal nutritional status; DHS comparative studies no 24. Calverton, Maryland: Macro International Inc., 1997.

31 Salomon JA, Murray CJL. The epidemiologic transition revisited: compositional models for causes of death by age and sex. Popul Dev Rev 2002;28:205-28.

32 Mathers CD, Loncar D. Projections of global mortality and burden of disease from 2002 to 2030. PLoS Med 2006;3:e442.

33 Republic of Botswana.. Botswana STEPS Survey: Chronic Risk factor Surveillance Report. Gaborone, Botswana: Ministry of Health, 2010.

34 Republic of Botswana. Botswana steps survey report on noncommunicable disease risk factors 2015. Gaborone, Botswana: Ministry of Health \& World Health Organisation, 2016.

35 Republic of Botswana. Botswana demographic survey 2017. Gaborone, Botswana: Statistics Botswana, 2018.

36 IBM Corp. IBM SPSS Statistics for Windows. Version 25.0. Armonk, NY: IBM Corp, 2017.

37 Janjua NZ, Mahmood B, Bhatti JA, et al. Association of household and community socioeconomic position and urbanicity with underweight and overweight among women in Pakistan. PLoS One 2015;10:e0122314.

38 Kamal SMM, Hassan CH, Alam GM. Dual burden of underweight and overweight among women in Bangladesh: patterns, prevalence, and sociodemographic correlates. J Health Popul Nutr 2015;33:92-105.

39 Biswas T, Garnett SP, Pervin S, et al. The prevalence of underweight, overweight and obesity in Bangladeshi adults: data from a national survey. PLoS One 2017;12:e0177395

40 Rawal LB, Kanda K, Mahumud RA, et al. Prevalence of underweight, overweight and obesity and their associated risk factors in Nepalese adults: data from a nationwide survey, 2016. PLoS One 2018;13:e0205912

41 Ogunbode AM, Ladipo M, Ajayi IO, et al. Obesity: an emerging disease. Niger J Clin Pract 2011;14:390-4.

42 Selassie M, Sinha AC. The epidemiology and aetiology of obesity: a global challenge. Best Pract Res Clin Anaesthesiol 2011;25:1-9.

43 Nguyen T, Lau DCW. The obesity epidemic and its impact on hypertension. Can J Cardiol 2012;28:326-33.

44 Navaneetham K, Keetile M, Letamo G, et al. Chronic NonCommunicable Diseases in Botswana: A Study of Prevalence, Healthcare Utilisation and Health Expenditure. Gaborone, Botswana, 2018.

45 Keetile M, Navaneetham K, Letamo G. Patterns and determinants of hypertension in Botswana. Z Gesundh Wiss 2015;23:311-8.

46 Feldblum I, German L, Castel H, et al. Characteristics of undernourished older medical patients and the identification of predictors for undernutrition status. Nutr J 2007;6:37.

47 Masella R, Malorni W. Gender-Related differences in dietary habits. Clinical Management Issues.2017;11:59-62.

48 Gurunathan U, Myles PS. Limitations of body mass index as an obesity measure of perioperative risk. $\mathrm{Br} J$ Anaesth 2016;116:319-21. 